\title{
ЭФФЕКТИВНОСТЬ ИСПОЛЬЗОВАНИЯ АППАРАТОВ МОКРОЙ ОЧИСТКИ ВЫБРОСНЫХ ГАЗОВ В ПРОМЫШЛЕННОСТИ ${ }^{1}$
}

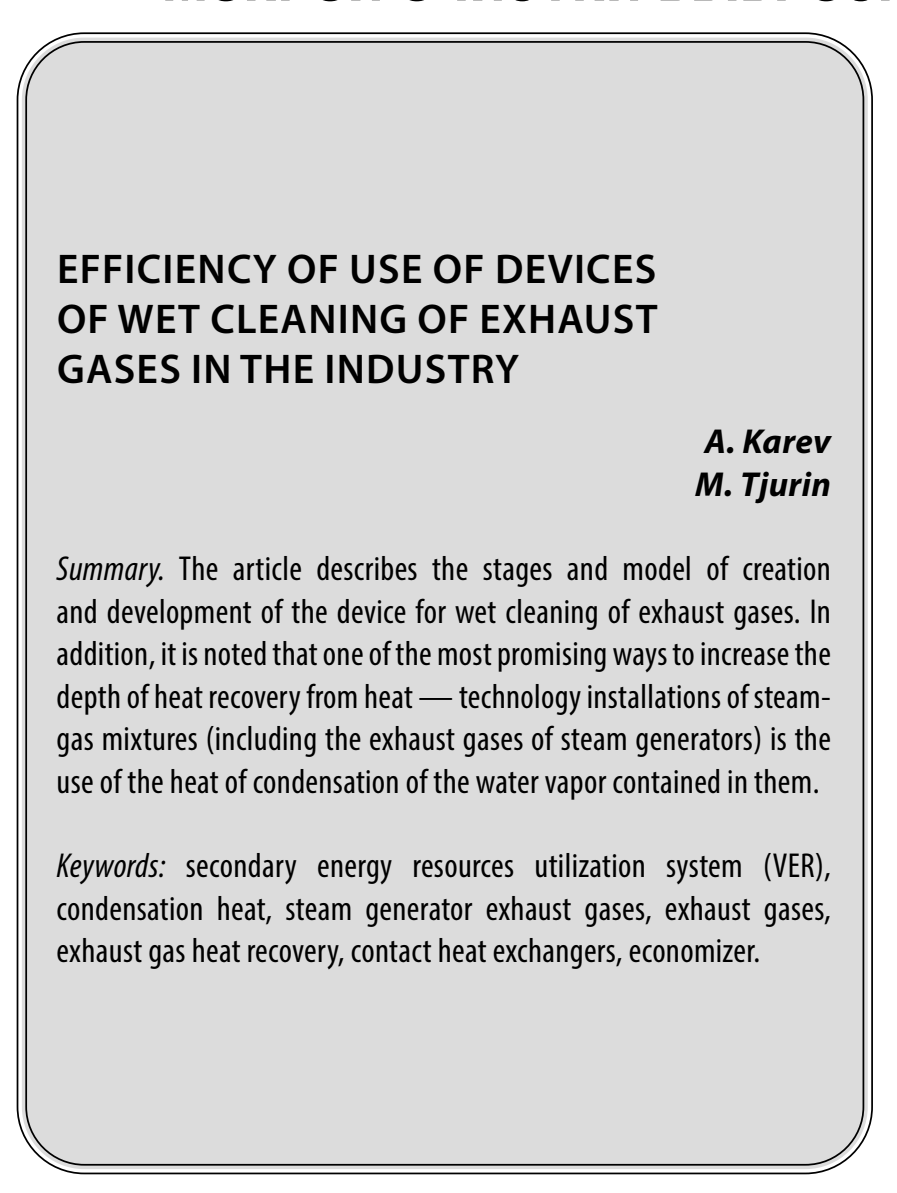

\section{Введение}

$\mathbf{K}$ ачество нашей жизни, наше здоровье зависят от постоянного притока чистого воздуха, необходимого нам для дыхания. Воздействие загрязненного воздуха, будь то долгосрочное промышленное загрязнение или единичный инцидент, может повлиять на здоровье на десятилетия вперед или даже привести к смерти.

Но воздух нужен не только для дыхания живых организмов. Он потребляется в огромных объемах в больших статических генераторах, вырабатывающих электроэнергию и в транспортных средствах. Любые твердые частицы в этом воздухе (или в жидком или га-
Карев Алексей Николаевич

Аспирант, ФГБОУ ВО «Российский государственный университет им. А.Н. Косыгина (Технологии. Дизайн. Искусство) alexcarew777@yandex.ru

тюрин Михаил Павлович

Д.т.н., профессор, ФГБОУ ВО «Российский государственный университет им. А.Н. Косыгина (Технологии. Дизайн. Искусство) tjurinmp@ya.ru

Аннотация. В статье рассмотрены этапы и модель создания и разработки аппарата мокрой очистки выбросных газов. Кроме этого, отмечено, что одним из наиболее перспективных путей повышения глубины утилизации теплоты, отходящих от теплотехнологических установок парогазовых смесей (в том числе - уходящих газов парогенераторов) является использование теплоты конденсации содержащихся в них водяных паров.

Ключевые слова: система утилизации вторичных энергетических ресурсов (ВЭР), теплота конденсации, уходящие газы парогенераторов, выбросные газы, утилизация теплоты выбросных газов, контактные теплообменники, экономайзер.

зообразном топливе) могут повлиять на эффективность и чистоту сгорания, а в некоторых случаях серьезно сократить срок службы деталей двигателя или турбины. Отходящие газы после сжигания, содержащие частицы сажи, а также опасные или вредные газы, представляют собой огромную экологическую проблему как в местной окружающей среде, так и с точки зрения их воздействия на региональном или даже глобальном уровнях.

Создание и совершенствование систем утилизации вторичных энергетических ресурсов (ВЭР) дает возможность наиболее полно удовлетворить потребность в энергии не путем ввода дополнительных мощностей, а за счет энергосбережения - одного из приоритетных направлений развития экономики России на современном этапе.

1 Информация о финансировании: Грант РФФИ - 20-38-90061 Аспиранты, № Договора 20-38-90061 20 от 31.08.2020 г. 
Одним из наиболее перспективных путей повышения глубины утилизации теплоты отходящих от теплотехнологических установок парогазовых смесей (в том числе - уходящих газов парогенераторов) является использование теплоты конденсации содержащихся в них водяных паров. Для этого применяются контактные теплообменники, позволяющие при достаточно приемлемых габаритах, умеренном расходе металла на их изготовление и сравнительно невысоком расходе электроэнергии при эксплуатации обеспечить глубокое охлаждение отходящих газов, конденсацию содержащихся в них водяных паров и возможность использования получаемого конденсата, то есть экономию воды.

Процесс тепломассообмена в контактных теплообменниках весьма сложен для математического моделирования [5]и расчета, так как общая интенсивность передачи теплоты в нём зависит от соотношения между собой значений трех тепловых потоков: передачи физической теплоты парогазовой смеси воде, испарения воды и конденсации паров. В зависимости от величин температур воды, газа и точки росы доминирующее влияние могут иметь процессы тепло- или массопереноса, причем в различных зонах аппарата движущие силы этих процессов могут иметь разные знаки. Поэтому очень трудно установить какие-либо четкие закономерности среднего для всей контактной камеры общего (условного) коэффициента теплоотдачи (учитывающего и массоотдачу). Универсальных надежных и общепризнанных зависимостей для определения таких коэффициентов нет и получить их по мнению автора диссертации [1]не представляется возможным вследствие большого количества независимых факторов, влияющих на интенсивность рассматриваемых процессов. До настоящего времени известные инженерные методики расчета таких аппаратов основаны на использовании средних по всему объему параметров: температурного напора, условного коэффициента теплоотдачи, эффективной площади контакта фаз и др.

\section{1. Основные типы контактных теплообменных аппаратов, их конструкции и приншип Аействия}

\section{1. Конструкция и эксплуатация скруббера}

Скрубберы - это устройства, которые используют жидкость (обычно воду) для улавливания и удаления загрязняющих веществ. Через сопло или отверстие очищающая жидкость распыляется и диспергируется в газовом потоке. Капельки улавливают и захватывают частицы пыли через агломерацию, прилипание или инкапсуляцию, что эффективно увеличивает размер и массу частиц, это облегчает их сбор в последующем процессе фильтрации или разделения. Очищающая жидкость одновременно поглощает и нейтрализует газообразные загрязняющие вещества. Суспендированная жидкость обычно извлекается в сборниках конденсата и рециркулируется через очистную системy.

\section{2. Достоинства и недостатки скрубберов}

Среди очевидных преимуществ отметим следующие:

1. Небольшие габариты установок, удобство их размещения в производстве: небольшие габариты устройств требуют меньших вложений при высокой мобильности конструкций по сравнению с установками такой же производительности, но другого типа работы;

2. Отсутствуют вторичные источники пыли и загрязнения: отходы упаковываются в бункер и вывозятся без протечек;

3. Возможна работа как с высокотемпературными, так и с сильно насыщенными потоками: в устройствах этого типа нет проблем с отводом конденсата и температурных ограничений (как, например, в электростатических отстойниках или рукавных фильтрах);

4. Максимальная взрыво- и пожаробезопасность: присутствие жидкой среды сводит на нет возможность детонации или возгорания в скруббеpe;

5. Универсальность: возможна работа как с газообразными химическими, так и с механическими загрязнителями различных фракций.

Однако имеются и некоторые недостатки, которые не уменьшают достоинства устройства. Понимание недостатков делает возможным применить меры по их минимизации, или выбрать соответствующие условия эксплуатации.

Недостатки, следующие:

1. Коррозия: в процессе работы могут образовываться высококоррозионные кислотные растворы. Данная проблема решается футеровкой рабочих частей корпуса;

2. Высокие требования к стабильному электроснабжению установок: эффективность захвата твердых частиц может быть достигнута только при высоких перепадах давления, что приводит к значительным эксплуатационным расходам на электроэнергию;

3. Загрязнение воды (особенно актуально для крупных промышленных комплексов): для выполнения требований по очистке сточных вод может 


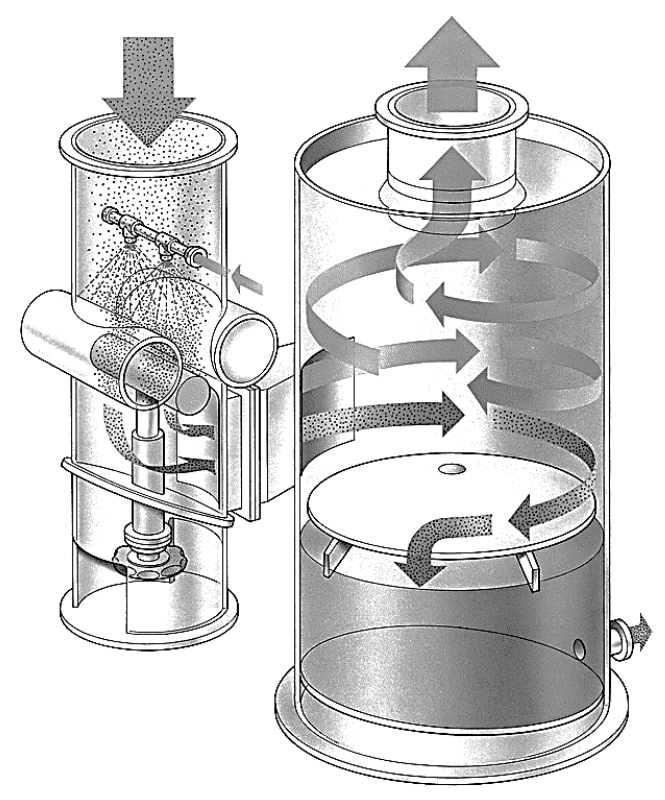

Рис. 1. Скруббер Вентури

потребоваться возведение отдельных очистных сооружений или специальных отстойников;

4. Проблемный выход побочного продукта из шлама: осушивание и дегидратация скрубберного шлама делают извлечение полезного продукта для повторного использования достаточно трудоемким.

\section{3. Типы скрубберов}

В своей статье Дипак К Саркар, опираясь на ряд обзорных исследований, дает описание нескольким типам скрубберов.

Распылительные башни. В распылительных башнях или распылительных камерах газовые потоки подаются в камеру и контактируют с очищающей жидкостью, производимой распылительными форсунками. Размер капель контролируется для оптимизации контакта частиц и отделения капель от газового потока. Камеры могут быть ориентированы на поперечный поток, противоточный поток или параллельный (сотоковый) поток. Камеры могут также включать дефлекторы для улучшения контакта газа и жидкости.

Распылительные башни имеют низкое энергопотребление, но при этом и относительно низкую эффективность сбора твердых частиц. Рециркулируемая вода в системе должна быть тщательно очищена, чтобы предотвратить чрезмерное загрязнение или засорение сопла. Очистка и замена сопел являются основной частью технического обслуживания, необходимого для агрегатов этого типа.
Орошаемые циклоны. Циклонные распылительные камеры - это скрубберы, которые сочетают в себе методы захвата циклонов и распылительных башен. Газовые потоки обычно входят в камеру тангенциально на высоких скоростях. Высокие скорости вызывают циклоническое действие, а центробежная сила способствует разделению капель, позволяя использовать меньший размер капель, что повышает эффективность сбора. Циклонные распылительные камеры более эффективны, чем распылительные башни. Они имеют более низкие требования к жидкости, но при этом из-за более высоких перепадов давления требуют большей мощности. По сравнению с распылительными башнями они более эффективны для газовых потоков с более тяжелыми частичными нагрузками.

Скруббер Вентури. Скрубберы Вентури - это воздушные скрубберы с камерой в форме Вентури со сходящимися и расходящимися секциями. Вода впрыскивается под низким давлением в горловину трубки Вентури, через которую с большой скоростью проходит газовый поток. Энергия от газа распыляет жидкость, позволяя частицам и загрязнителям быть захваченными в каплях. Струйные скрубберы Вентури используют модифицированную конструкцию, в которой жидкость впрыскивается в горловину с высокой скоростью, а не в газовый поток.

Скрубберы Вентури обладают высокой эффективностью сбора загрязняющих частиц и просты в установке и обслуживании. Однако они требуют больших перепадов давления, что приводит к более высоким требованиям к мощности, чем другие модели. 
Диафрагменные скрубберы. Эти скрубберы похожи на скрубберы Вентури в том, что поток газа протекает с высокой скоростью через узкое отверстие для распыления жидкости в капли. Прежде чем попасть в отверстие, газ с высокой скоростью движется через емкости с очищающей жидкостью. По мере того, как он выходит из емкости, капельки и загрязняющие вещества оседают на ряде перегородок. Этот скруббер обладает таким преимуществом как низкая скорость рециркуляции воды.

Ударные скрубберы. Ударные или перфорированные пластинчатые скрубберы представляют собой разновидность скрубберов с регулируемыми отверстиями для изменения скорости удара.

Насадочные скрубберы, или скрубберы с насадочным слоем. Они представляют собой камеры, содержащие один или несколько слоев упаковочного материала для увеличения газожидкостного контакта, таких как кольца Рашига, спиральные кольца или седла Берла. Газовые потоки поступают в нижнюю часть камеры и текут вверх (противотоком) или горизонтально (поперечным потоком) через насадку, так как очищающая жидкость равномерно распределяется по упаковочному материалу. После прохождения упаковки очищенный газ проходит через уловитель, а отработанная жидкость/суспензия самотеком падает на дно. Скрубберы с насадочным слоем являются в первую очередь газопоглотителями, они предназначены для очистки газовых потоков от газообразных загрязняющих веществ. При этом они могут собирать и твердые частицы, но для этой функции они не очень эффективны, так как мокрая пыль, собирающаяся в пластах, требует специальной очистки.

Сухие скрубберы. Выше были описаны виды наиболее распространенных и хорошо известных «мокрых» скрубберов. Однако в последнее время термин «скруббер» также используется для описания устройств для загрязнения воздуха, которые впрыскивают сухой сорбент или распыляют его в газовый поток. Сухие скрубберы применяются для удаления кислых и пахучих газов из котлов, мусоросжигательных установок и очистных сооружений сточных вод. Инжекторы сухого сорбента впрыскивают щелочной материал в газовый поток для взаимодействия с кислыми газами. В результате реакции образуются твердые соли, которые удаляются в устройстве контроля твердых частиц системы. Эффективность этих устройств может быть повышена путем увеличения влажности или использования мокрой очистки в дополнение к сухому впрыску.

Распылительные сушилки / сухие скрубберы. Данный вид скрубберов используется для контроля тяжелых металлов. Распылительные сушилки впрыскивают щелочную суспензию в газовый поток, в результате чего вода в суспензии испаряется, что приводит к охлаждению газов сгорания. Это охлаждение существенно обезвоживает тяжелые металлы, позволяя им конденсироваться в твердые частицы, которые затем легко захватываются электростатическим осадителем или тканевым фильтром. Этот метод сбора обычно обеспечивает эффективность удаления около 99 процентов. Однако эффективность удаления ртути составляет лишь около 50 процентов, что составляет существенный недостаток из-за высокой токсичности ртути.

Применение тканевых фильтров является относительно новым способом удаления загрязнений. Данные фильтры проанализированы в работе, в частности, указано, что многие недостатки использования тканевых фильтров устраняются или существенно уменьшаются за счет внедрения комбинированных систем. Такие комбинированные системы не подвержены пожарам из-за длительного времени удержания пыли в распылительной сушилке и за счет охлаждения газов. Поэтому высокие температурные отклонения здесь маловероятны. Кроме того, добавление щелочного реагента приводит к более эффективным фильтрующим характеристикам и снижению коррозионного потенциала.

Преимущества полусухой системы скруббера / тканевого фильтра заключаются в следующем:

- Одновременное удаление кислого газа и твердых частиц;

- Снижение коррозионного потенциала позволяет более широко использовать строительные материалы, снижает капитальные затраты. Затраты на техническое обслуживание также снижаются;

- Увеличивается срок службы оборудования;

- Температура дымовых газов выше точки росы, что приводит к отсутствию видимого шлейфа конденсации;

- Повторный нагрев дымовых газов обычно не требуется для подъема шлей $ф а ; ~$

- Высокая эффективность удаления твердых частиц, включая очень мелкие частицы и микроэлементы; в результате остается сухой стабильный остаток, требующий менее дорогостоящую утилизацию.

Система полусухого скруббера имеет некоторые недостатки, которые заключаются в следующем:

- Возможность засорения и эрозии инжекционных сопел из-за абразивных характеристик суспензии;

- Потенциал для образования шлама или частиц на стенках камеры и воздуховодов; 
- Появление «слепых» мешков, если влага суспензии не испаряется полностью;

- Высокое использование реагента, так как реагент не перерабатывается.

Сухие скрубберы - это многоциклонные (многоклонные) инерционные сепараторы, которые удаляют как жидкости, так и твердые материалы без использования очищающих масел или жидкостей. Они практически не требуют технического обслуживания, за исключением продувки сливного бачка.

Преимущество мокрых скрубберов состоит в том, что они, как правило, дешевле полусухих и сухих скрубберов; однако недостатком является то, что они производят сточные воды, которые должны быть обработаны и сброшены. Полусухие и сухие скрубберы менее подвержены коррозии и не выделяют сточные воды; однако они потребляют больше химических веществ и дают твердые остатки

Циклоны, тканевые фильтровальные мешки и ESP удаляют твердые частицы (ТЧ) и летучую золу из дымовых газов. Циклоны состоят из цилиндрической камеры и удаляют ТЧ из дымовых газов по инерции. Из-за их ограниченной эффективности удаления они используются в установках в качестве дополнения к другим стадиям очистки дымовых газов. Тканевые фильтровальные мешки являются наиболее часто используемым оборудованием, поскольку они обладают высокой эффективностью удаления твердых частиц для крупных и мелких частиц. Частицы улавливаются в серии фильтровальных мешков, когда дымовой газ проходит через них, а затем воздух продувается в противоположном направлении, чтобы очистить фильтры и собрать пыль. ESP использует высокое электрическое напряжение для зарядки частиц и осаждения их на электрод для сбора. ESP имеет ограниченную эффективность в удалении мелких частиц и часто устанавливается вместе с тканевыми фильтровальными мешками, чтобы соответствовать строгим ограничениям выбросов.

Каталитическое восстановление, активированный уголь и впрыск сухого сорбента используются для уменьшения содержания NOx и удаления тяжелых металлов, диоксинов/фуранов и ТЧ соответственно. NOx может быть разрушен с помощью селективного некаталитического восстановления (SNCR) или селективного каталитического восстановления (SCR). SNCR использует сухую мочевину NH3 в качестве восстановителя при температурах от 900 до $1050^{\circ} \mathrm{C}$ для образования воды и N2, в то время как SCR использует катализатор, такой как смесь NH3 и воздуха, для образования кислорода и воды. SNCR дешевле и дает меньше проблем с коррозией, в то время как SCR более эффективен, дости- гая скорости снижения до 85\%. Активированный уголь и щелочные сорбенты, такие как известь и $\mathrm{NaOH}$, вводятся в дымовые газы для удаления летучих тяжелых металлов и кислых газов.

Щелочные металлы не входят в число основных загрязнителей, но они тесно связаны с выбросами ТЧ. Щелочи, которые способствуют шлакообразованию в системах термической обработки отходов,- это калий (K), $\mathrm{Na}, \mathrm{Cl}$ и кремнезем. Пары щелочи могут химически ухудшать эффективность керамических барьерных фильтров, используемых для удаления ТЧ в системах очистки горячего синтез-газа. Пары щелочи направляются через охлаждение синтез-газа перед использованием в турбинах. Связанные с этим потери энергии привели к исследованию альтернатив, которые включают использование керамических фильтров, называемых "геттерными слоями", которые могут переносить высокие температуры.

Одно из перспективных направлений - усовершенствование и разработка новых конструкций центробежно-инерционных пылеуловителей. Исследованию пылеулавливания и разработке новых пылеуловителей циклонного типа были посвящены работы Набила Харуа, Лиса Хеззара, Зубира Немути [4]. В статье представлены результаты исследований процесса улавливания летучей золы на примере экспериментальной модели электроциклона. Было выяснено, что в разработанной конструкции аппарата степень очистки в режиме электроциклона намного выше - близка к 100\%, чем в режиме циклона - 90-90\%. В статье представлены результаты численного моделирования и экспериментального исследования динамики аэродинамического давления - одного из главных параметров характеристик циклонов с использованием численного моделирования гидродинамики потока очищенного газа (CFD) с учетом изменения напряжения Рейнольдса. (RSM). В статье рассмотрена теоретическая модель с использованием параметра времени пребывания частиц в устройствах (среднее время пребывания) для расчета эффективности улавливания циклоном, а также представлены результаты разработки и испытаний циклонного сепаратора, область аэродинамических режимов, для которых задавался диапазон расходов воздуха от 10 до 100 л / мин с достижением максимально возможной эффективности улавливания пылевых частиц мелких фракций (1-10 мкм) малой плотности. Продолжаются исследования по разработке новых конструкций центробежно-инерционных устройств для мокрой очистки газов (циклонов скрубберов) с использованием методов численного моделирования, описания и расчета пылеулавливания. Например, представлены результаты исследования численного решения уравнений Эйлера, описывающие гидродинамику течения 
трехфазных потоков (газ - жидкость - твердое тело) и оценивающие эффективность очистки газового потока от пыли в мокром скруббере.

Аппараты мокрой очистки работают по принципу осаждения частиц пыли либо на поверхность капель жидкости, либо на поверхность плёнки жидкости. Осаждение частиц пыли на жидкость происходит под действием сил инерции и броуновского движения. Кроме этих основных сил на процесс осаждения влияют турбулентная диффузия, взаимодействие электрически заряженных частиц, процессы конденсации. Во всех случаях очистки газа в мокрых пылеуловителях важным фактором является смачиваемость частиц жидкостью - чем лучше смачиваемость, тем эффективнее процесс очистки.

Преимуществами аппаратов мокрой очистки можно считать следующее:

- сравнительно небольшую стоимость (без учета шламового хозяйства) и более высокая эффективность улавливания по сравнению с сухими пылеуловителями;

- возможность очистки газов от частиц размером до 0,1 мкм;

- охлаждение и увлажнение (кондиционирование) газов;

- возможность применения для очистки газов с высокой температурой;

- возможность одновременной очистки от пыли и некоторых газообразных вредных веществ.

К недостаткам мокрых пылеуловителей относятся:

- улавливаемый аппаратами мокрой очистки продукт выделяется в виде шлама, что связано с необходимостью обработки сточных вод;

- потери орошающей жидкости в результате брызгоуноса;

- необходимость антикоррозионной защиты оборудования при очистке агрессивных газов и смесей.

Отмечено, что значительно лучшие условия эксплуатации контактного экономайзера создаются, если применять промежуточный теплообменник, обеспечивающий независимость работы экономайзера от расхода воды потребителями. Необходимо осуществлять комплексную поставку: циркуляционный насос, экономайзер, теплообменник. Помимо этого, рекомендуется оснащать экономайзер переливной трубой с гидрозатвором и водомерным стеклом.

При всей своей высокой тепловой эффективности, насадочные противоточные теплоутилизаторы (экономайзеры) имеют недостатки, главный из которых заключается в том, что качество нагретой контактным способом воды не удовлетворяет требованиям ГОСТ 2874-82*.

Для того, чтобы снять ограничения по качеству нагреваемой воды теплоутилизационные установки с «пассивной» насадкой необходимо применять совместно с промежуточным теплообменником. Установка промежуточного теплообменника совместно с теплоутилизатором [8] исключает прямой контакт газов с нагреваемой для целей теплоснабжения водой. Промежуточный теплообменник бывает встроенным в корпус контактного теплоутилизатора или монтируется отдельно, в зависимости от того, какой мощности котел используется, а также в зависимости от теплопроизводительности утилизатора.

Ранее для глубокого охлаждения дымовых газов ниже точки росы использовались теплообменники контактного типа (насадочные, пенные, барботажные, форсуночные и тарельчатые). В последнее десятилетие получили распространение конденсационные поверхностные экономайзеры, которые также позволяют охлаждать уходящие дымовые газы ниже температуры точки росы. Конденсационные котлы и экономайзеры [2] изготавливаются из различных материалов. Но, поскольку выделяющийся из продуктов сгорания конденсат имеет кислую реакцию, общим для них является высокая коррозийная стойкость. Это нержавеющая сталь, чугун, медь, полимерные материалы и даже керамика. Применение коррозионностойких материалов позволяет создать конденсационные теплообменники и для утилизации теплоты уходящих газов жидкого топлива.

Опытные данные и сопоставление результатов расчетов контактного утилизатора марки ЭК-БМ-1-1, имеющего диаметр 1000 мм, с результатами его испытаний, выполненных в производственных условиях, приведены в работе, а также в статье П.А. Мищенко «Опыт реконструкции аппаратов мокрой очистки газа на основе вихревых скрубберов». В статье изложены результаты проведенной серии экспериментов, по которым аппараты были доработаны для дальнейшей эксплуатации. Для предупреждения забивания пульповыводящего отверстия и снижения каплеуноса предложено плоское днище аппарата заменить на конусообразный вариант. Во избежание абразивного износа водоподводящего канала внутрь вихревого модуля вставили трубу, так чтобы поток газа не соприкасался с верхним основанием завихрителя. Постоянно проводящиеся в Институте теплофизики СО РАН исследования и разработки ВС позволяют рассчитывать на создание наиболее оптимального вихревого аппарата, способного заменить многие устройства мокрой очистки газов, применяющиеся в отечественной теплоэнергетике. 
ЛИТЕРАТУРА

1. Якимычев П.В. Совершенствование методов моделирования и расчета процессов тепломассопереноса в контактных теплообменниках. Дисс. кандидата технических наук; Иваново 2012

2. Аронов, И.З. Прямоточные и прямоточно-противоточные контактные экономайзеры для промышленных котлов/И.3. Аронов//Газовая промышленность. - 1968. — № 5. - с. 43-46.

3. Захарова, 3.Л. Газовые контактные водонагреватели и их применение в народном хозяйстве/3.Л. Захарова, А.В. Рачинский, П.А. Кузьмин — Л.: Недра. - 1966. - 144 c.

4. Кудинов А.А., Энергосбережение в теплогенерирующих установках. - М.: Машиностроение, 2012. - 139 с.

5. Мизонов, В.Е. Моделирование и оптимизация теплового состояния в секционированных объемах с внутренними источниками теплоты. Монография/В.Е. Мизонов, Н.Н. Елин, Е.А. Баранцева.— ГОУВПО «Ивановский государственный энергетический университет», Иваново, 2018. — 128 c. ISBN9785-89482-693-6

6. Мизонов, В.Е. Моделирование, расчет и оптимизация тепломассообменных процессов в текстильной промышленности. Монография/В.Е. Мизонов, В.А. Зайцев, В.Ю. Волынский, СП. Бобков - ГОУВПО «Ивановский государственный химико-технологический университет», «Ивановский государственный энергетический университет» Иваново, 2018. - 204 c. ISBN978-5-9616-0350-7.

7. Шадек Е., Маршак Б. Глубокая утилизация тепла отходящих газов теплогенераторов / Промышленные и отопительные котельные и мини-ТЭц.2014. Научно-технический журнал «СОК»№ 2.

8. Шадек Е., Маршак Б., Крыкин И., Горшков В. Конденсационный теплообменник-утилизатор - модернизация котельных установок // Промышленные и отопительные котельные и мини-ТЭЦ, 2014.№ 3 (24).

9. Якимычев П.В. Совершенствование методов моделирования и расчета процессов тепломассопереноса в контактных теплообменниках. Дисс кандидата технических наук; Иваново 2012

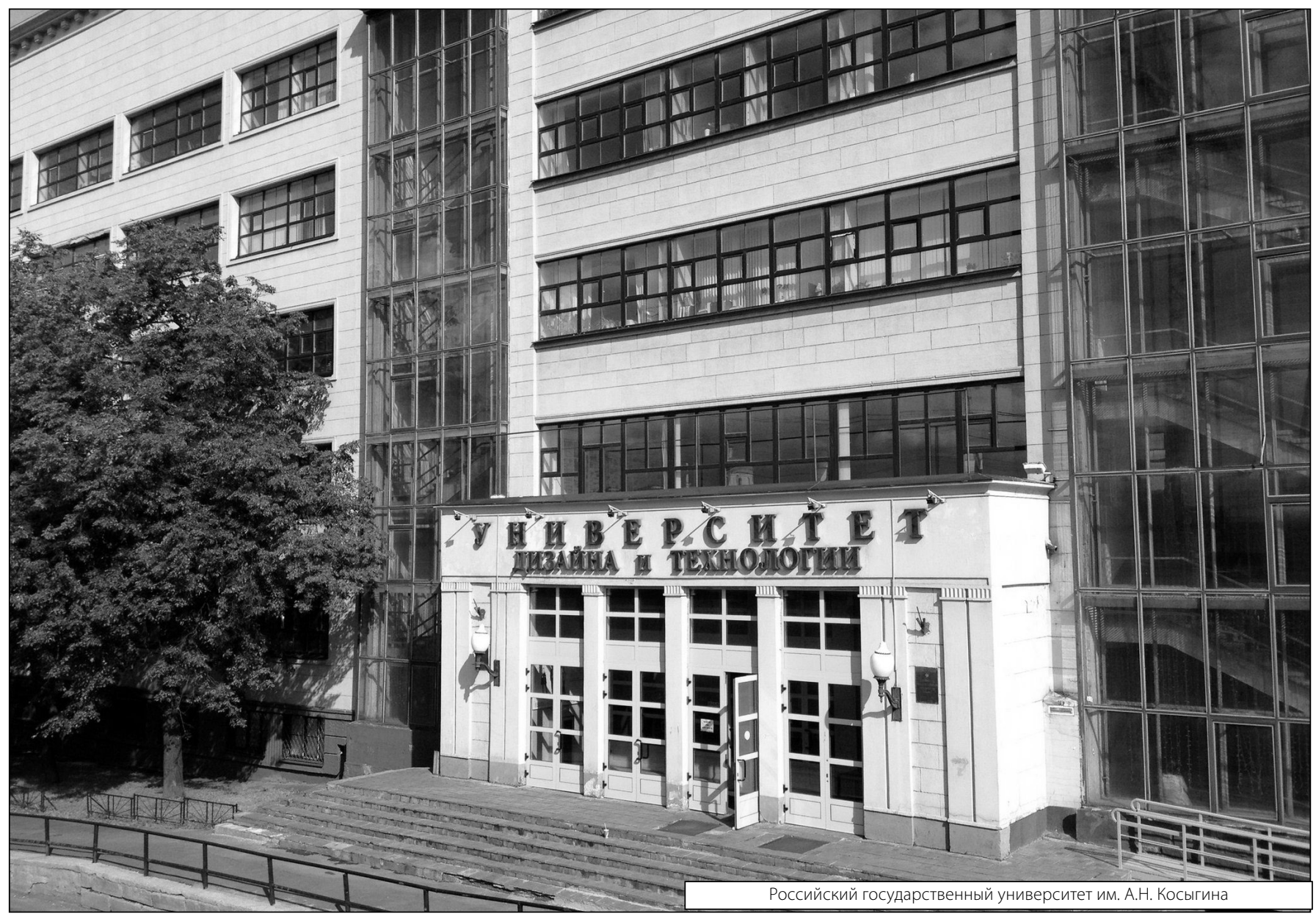

